\title{
Phenology, Within-Vineyard Distribution, and Seasonal Movement of Eastern Grape Leafhopper (Homoptera: Cicadellidae) in New York Vineyards
}

\author{
TIMOTHY E. MARTINSON, TIMOTHY J. DENNEHY, AND CHRISTOPHER J. HOFFMAN ${ }^{1}$
}

Department of Entomology, Cornell University, New York State Agricultural Experiment Station, Geneva, NY 14456

\begin{abstract}
Environ. Entomol. 23(2): 236-243 (1994)
ABSTRACT Seasonal changes in within-vineyard distribution and abundance of Erythroneura comes (Say) adults and nymphs were investigated from 1989 to 1992 . Trap catches of adults were highest in May and were concentrated in wooded areas next to vineyards. In 1989 and 1990 surveys, nymphal densities did not decline as distance from the vineyard edge increased. In 1991, however, nymphal densities were significantly higher at vineyard edges than in vineyard interiors in July, suggesting that oviposition initially was aggregated at vineyard edges. Subsequently, nymphal densities at vineyard edges and interiors were similar. Cumulative degree days (DD) for mean observation of first nymphs, firstgeneration, and second-generation peak populations, sampled at 14 vineyards in 1989 , 1990 , and 1991 , were $390 \pm 71,648 \pm 86$, and $1,190 \pm 154 \mathrm{DD}$ (mean $\pm \mathrm{SD}$; base $10^{\circ} \mathrm{C}$ ), respectively. Nymphal densities exceeded a provisional threshold of five per leaf in only $2,25,13$, and $8 \%$ of vineyards untreated with insecticides in 1989, 1990, 1991, and 1992 , respectively. These results show that leafhoppers do not cause economic injury in most New York vineyards in most years. Reduced insecticide strategies recently implemented for grape berry moth control will not greatly increase the need for insecticide applications directed at leafhoppers in New York.
\end{abstract}

KEY WORDS Vitis, Erythroneura comes, grapes

From THE LATE 1940s until the mid 1980s, arthropod control programs in grapes in northeastern North America have been based on three insecticide sprays timed to control grape berry moth, Endopiza viteana Clemens, the key arthropod pest of New York grapes (Taschenberg 1948). This treatment regime also provided incidental control of six secondary and occasional pests of grape, the most important of which is the eastern grape leafhopper, Erythroneura comes (Say). Recently, Hoffman \& Dennehy (1989) showed that this treatment regime was unnecessary in a large percentage of New York vineyards. New recommendations were developed to target insecticide treatments in vineyards where they were needed most, based on a risk assessment procedure (Hoffman \& Dennehy 1987, Martinson et al. 1991). The Grape Berry Moth Risk Assessment Program has resulted in a $70 \%$ reduction in insecticide use, based on vineyards enrolled in the Cornell Grape IPM Program (Martinson et al. 1991). Mating disruption, using the newly registered pheromone product ISOMATE-GBM (Microflo, Lakeland, FL), has also been shown to be a viable alternative to conventional insecticides used

${ }^{1}$ Current address: Seminar Graphics, 213 Monevista Drive, Aptos, CA 95003. to control grape berry moth (Dennehy et al 1991). These recent developments in managing grape arthropods in New York have prompted a reevaluation of the pest status of $E$. comes. Specifically, concern has been voiced by growers that eastern grape leafhopper will increase in importance as minimal-insecticide strategies continue to gain acceptance.

Eastern grape leafhopper feeds on leaf mesophyll cells. The resulting stippling reduces photosynthesis and transpiration in individual leaves roughly in proportion to the amount of stippling visible (A. Lakso \& T.E.M., unpublished data). As a result, severe leafhopper injury was concluded to result in yield losses through reduced accumulation of soluble solids (Taschenberg \& Hartzell 1949). More recently, however, field studies of Jubb et al. (1983) showed little difference in yield and sugar content between balanced-pruned vines with and without leafhopper injury. However, since the study of Jubb et al. (1983), viticultural practices have changed greatly. Mechanical pruning, which increases yield potential in 'Concord' grapes by $40 \%$ over hand pruning (Pool et al. 1993), is gradually replacing hand pruning. As a result, the ratio of photosynthetically active leaf area to crop load has been greatly reduced in 
mechanically pruned vines. This higher crop load can lead to maturity problems in some years, and cluster thinning to reduce crop load during the growing season is often necessary to produce fruit mature enough to meet processors' standards for soluble solids (Pool et al. 1993). Because these new cultural practices place greater physiological stress on vines, stress associated with leafhopper feeding undoubtedly contributes to economic losses more often than was the case a decade ago.

By adopting reduced-insecticide use strategies to manage grape berry moth, growers can largely eliminate insecticide treatments in the twothirds of New York vineyards that are classified as low-risk (Martinson et al. 1991). As a result, noticeable leafhopper injury will appear in vineyards more frequently than in the past. The pest management challenge is to define the conditions under which intervention to control leafhoppers is economically justified. Thus, management recommendations specifically tailored to control eastern grape leafhopper are needed. These include optimal timing of insecticide sprays for leafhoppers, treatment thresholds, and workable sampling methods. Herein we report results of studies to determine seasonal movement, within-vineyard distribution, abundance in untreated vineyards, and phenology of eastern grape leafhopper, to provide a foundation for such recommendations.

\section{Materials and Methods}

Trapping of Adults. Phenology and movement of leafhopper adults were monitored in two vineyards in 1990 and in four vineyards in 1991. All vineyard blocks were bordered on one edge by woodlots, and no insecticide treatments were made in any of the blocks. Leafhopper adults were captured on yellow sticky panels, 15.5 by $29.5 \mathrm{~cm}$ (Olsen Products, Medina, $\mathrm{OH}$ ), placed 2 $m$ above the ground on wooden stakes $35 \mathrm{~cm}$ long mounted at the top of trellis posts. In each vineyard block, two transects of four sticky panels were placed perpendicular to the wooded edge, with $30 \mathrm{~m}$ between transects. Traps within transects were placed adjacent to the woods, on the first vineyard post, and at 20 and $50 \mathrm{~m}$ into the vineyard. They were replaced weekly from 15 May through 30 October in 1989 and 1990, except where noted in the Results. Adults were identified (Van Kirk et al. 1984) and counted using a binocular dissecting microscope.

Sampling of Nymphs. Seasonal trends in population densities of leafhopper nymphs and their distribution within vineyards were determined throughout the growing season by direct counts. From each vine sampled, one shoot was chosen randomly and nymphs on leaf nodes 3 to 7 (counting from the base of the shoot) were counted. The number of vines sampled in this manner and the location of the sampling units varied from year to year. In 1989 and 1990, nymphs were sampled at two and four vineyards, respectively. In each vineyard, 12 transects (eight transects in Catawba 1989; 14 in Diamond 1989) of five vines each were sampled, to map the distribution of nymphs with respect to the wooded vineyard edges. In each transect, the first, third, fifth, tenth, and twentieth vines from the vineyard edge were sampled. Vines were spaced $2.5 \mathrm{~m}$ apart in the row, with $2.8 \mathrm{~m}$ between rows. Nymphs were sampled twice weekly at each vineyard from 1 June to 1 July. Thereafter, vineyards were sampled weekly through 15 September.

In 1991, seasonal trends and within-vineyard distribution of nymphs were monitored in 12 vineyards enrolled in the Cornell IPM program's Pheromone Mating Disruption Demonstration Project. At each vineyard, nymphs were sampled on one shoot of each of five vines, at four sampling locations per vineyard. In accordance with the standard sampling procedure for grape berry moth, two sampling sites were located at the vineyard edge (first five vines from the vineyard edge) and two were located in the interior of the vineyard, at least 20 vines from the vineyard edge. Vineyards were sampled twice weekly from 1 June to 30 June and once a week through August. Sampling was terminated in early August at five of the 12 vineyards, because insecticide applications had eliminated leafhopper nymphs.

Regional Surveys of Nymphs. Surveys of densities of leafhopper nymphs were made in 23 to 43 vineyards untreated with insecticides in the Finger Lakes and Lake Erie regions of New York in 1989,1990, 1991, and 1992. At each survey site, counts were made of all nymphs on leaves of nodes 3-7 (counting from the shoot base) of one shoot on each of five vines in four different locations in the vineyard. In 1989 and 1990, each vineyard was sampled in mid-July and midAugust, when peak populations of nymphs were present. In 1991 and 1992, vineyards were sampled every 2 wk from 10 June through 15 September. From these data, the highest density of nymphs recorded during the season was selected to compare leafhopper severity among the vineyards surveyed.

Data Analysis. Weekly nymphal counts from 1989 and 1990 were analyzed to determine whether nymphal densities were similar at different distances from the wooded edge of vineyard blocks. Nymphal counts were pooled by month, and counts for each month were subjected to analysis of variance, with distance from the edge as a categorical treatment factor. Low $F$ statistics and high probability values $(P>0.01)$ were interpreted to mean that nymphs were not aggregated at any point along the transect perpendicular to the wooded edges. Means and standard errors of adult leafhoppers per trap per week at different distances from the vineyard 
edge were calculated. Trends in distribution were identified from the means and associated standard errors. The limited number of transects $(n=2)$ did not allow analysis of variance of these data, but each mean reported is based on captures from two traps, replaced weekly (eight traps total per distance) during each month.

To contrast nymphal densities at vineyard edges and interiors in 1991, data from the 12 vineyards were combined in one analysis. Nymph counts ( $n=10$ per sampling location) from June, July, and August were pooled within each month and subjected to two-way analysis of variance with vineyard and location within vineyard (edge or interior) as categorical treatment factors. Data from each month were analyzed separately, and mean nymphal densities ( \pm SEM) are reported here.

Degree-day accumulations were determined from weather data collected at weather stations located within 1 to $20 \mathrm{~km}$ of the vineyards sampled. A sine-wave approximation (Baskerville \& Emin 1969) was used to calculate degree-days, using a base temperature of $10^{\circ} \mathrm{C}$. This base temperature was chosen because it was shown to be the developmental threshold for the closely related species E. elegantula Osborn (Cate 1975). Cumulative degree-days were calculated from 1 April. Mean degree day accumulations ( \pm SD) were calculated for first observation of leafhopper nymphs and for the first- and secondgeneration population peaks. Peak nymph counts occurring after 1 August were assumed to represent second-generation nymphs. Some vineyards did not always have a discernible peak density during the first generation; data from these vineyards were not used in calculating mean degree-days for first-generation peak populations of nymphs. In vineyard 3 (1990), sampling started after 15 June, and nymphs were detected during the first sampling period. Data from vineyard 3 were not included in calculations of first observation of nymphs.

\section{Results}

Trap Catches of Adults. Mean numbers of adults captured per trap per week in 1989 and 1990 are shown in Fig. 1. In all six vineyards, trap catches were highest in May, declined rapidly in June, and remained low throughout the remainder of the growing season. Comparison of adult trap catches with nymphal densities (Fig. 1) shows that the number of adults trapped was not closely correlated with leafhopper densities in the vineyards. Few adults were trapped even in vineyards that had high densities of nymphs and where adults were observed to be abundant from mid-July through the end of the season (Fig. 1C, D). The highest catches of adults occurred in May, during the early stages of seasonal vine development.
Distribution of adult trap catches with respect to the wooded edges is shown in Table 1. At all vineyards, more adults were captured in May at the edge of the woodlot than in the vineyard. This trend was most striking at Diamond 1989, where 222.5 adults per trap were captured at the wooded edge, and $30.8,18.0$, and 14.3 adults were captured at the vineyard edge, $20 \mathrm{~m}$, and 50 $\mathrm{m}$ from the edge, respectively. In subsequent months, the numbers of adults captured declined greatly, and captures were also either more evenly distributed throughout the vineyard or higher in interior areas. In two of the six vineyards (Diamond 1989 and Concord-1 1990), again more adults were trapped at the wooded edge than in interior traps in October, which probably reflected movement of diapausing adults back into overwintering areas in wooded hedgerows.

Population Trends of Nymphs. Dates and degree-day accumulations (base $10^{\circ} \mathrm{C}$ ) for first observation of nymphs and first- and second-generation peaks are shown in Table 2 . On average, nymphs first appeared on 14 June $(S D=4 \mathrm{~d}$; range, 11-27 June). The first-generation population peak occurred on $6 \mathrm{July}$ ( $\mathrm{SD}=8 \mathrm{~d}$; range, 25 June-17 July), and second-generation peak occurred on 26 August (SD $=14 \mathrm{~d}$; range, $7 \mathrm{Au}$ gust-23 September). Date of first appearance of nymphs in the vineyards remained remarkably consistent over all years, in spite of variable weather conditions and vine phenology. Degreeday (DD) accumulations for first appearance of nymphs ranged from 264 to $450 \mathrm{DD}$ (mean $=390$; $\mathrm{SD}=71$ ). Peak population densities of the first generation occurred between 552 and 813 DD (mean $=648 ; \mathrm{SD}=86$ ). Peak second-generation population densities occurred between 887 and $1,356 \mathrm{DD}$ (mean $=1,190 ; \mathrm{SD}=154$ ).

Within-Vineyard Distribution of Nymphs. At the Catawba vineyard in 1989 , no trends in nymphal densities at different distances from the vineyard edge were apparent during any month (Table 3). At Diamond, nymphal densities were higher on vines 10 and 20 than on vines closer to the wooded vineyard edge. We attribute this pattern to preference of the leafhoppers for the variety 'Diamond'. 'Dutchess' was planted in the first eight rows of the Diamond vineyard, whereas vines in rows 10 and 20 were planted to 'Diamond'. This varietal difference was evident in a comparison of nymphal densities, which were 7-fold greater in 'Diamond' than in 'Dutchess' (Fig. 1B). In 1990, mean leafhopper densities were often significantly different between vineyard perimeters and interiors, with densities tending to be higher in interiors at all four vineyards surveyed. Higher densities away from the edge were observed in July and August at Concord-2 and Delaware and in August and September at Catawba and Concord-1 (Table 3). 

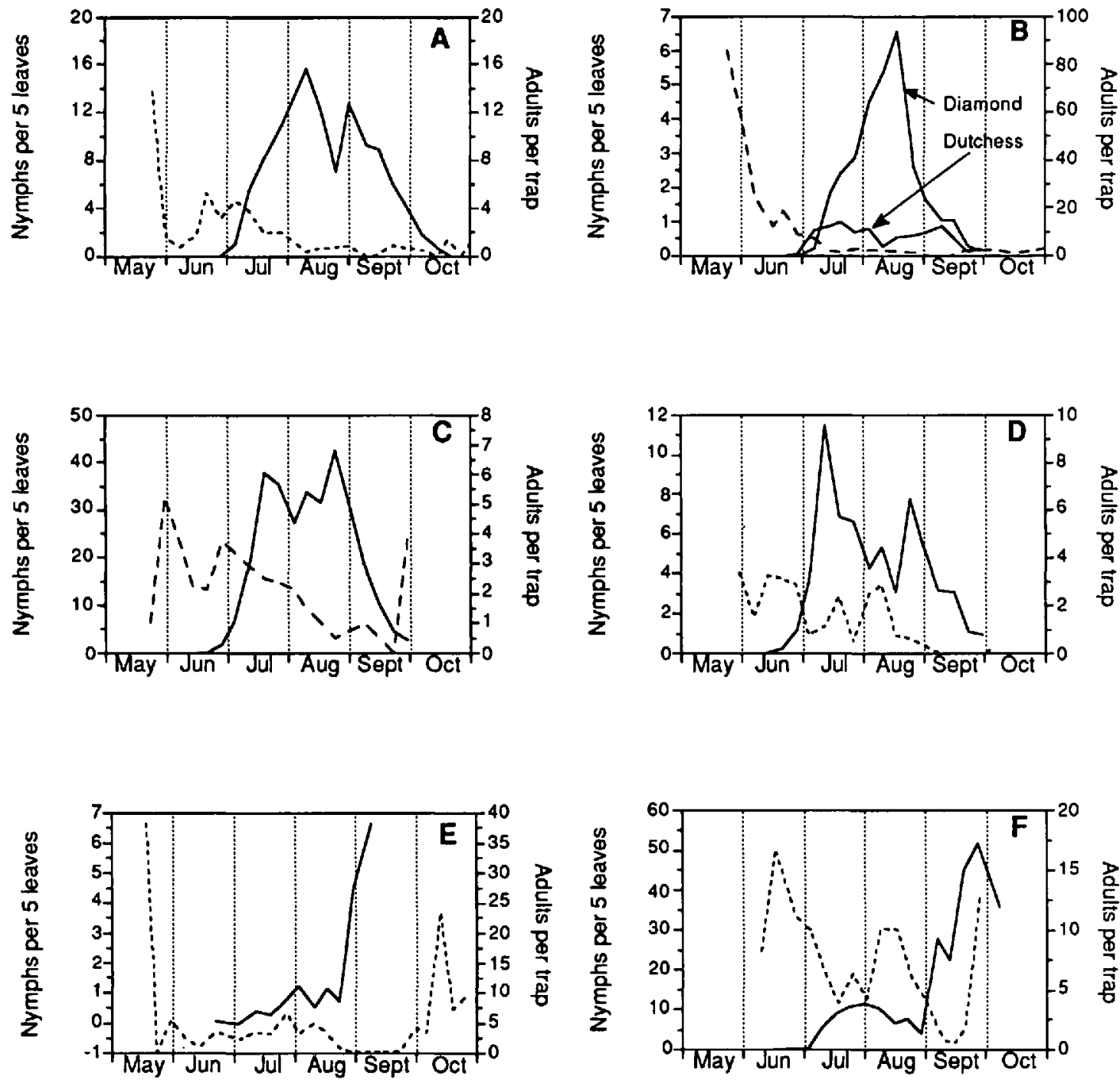

Fig. 1. Seasonal trap catches of $E$. comes adults (dashed lines) and densities of nymphs (solid lines) in six vineyards sampled in 1989 and 1990 in central New York. Varieties are as follows: A, 'Catawba' 1989; B, 'Diamond' and 'Dutchess' 1989; C, 'Catawba' 1990; D, 'Delaware' 1990; E, 'Concord'-1 1990; F, 'Concord'-2 1990.

Analysis of the 1991 nymphal data revealed trends different from those in 1989 and 1990. Nymphal densities at edge vines were not significantly different than densities in vineyard interiors in June $(F=2.27 ; \mathrm{df}=1,216 ; P=0.13)$ or August $(F=0.40 ; \mathrm{df}=1,139 ; P=0.52)$ (Table 4). In July, however, nymphal densities were significantly higher at the edge $(F=11.05 ; \mathrm{df}=1,216$; $P<0.001$ ). Thus, in 1991 there was a consistent, moderate edge effect during July, presumably reflecting aggregation of adults at vineyard edges early in the season and subsequent aggregation of oviposition there.

Regional Surveys of Leafhopper Densities. Maximum densities of leafhopper nymphs monitored in vineyards that had not been treated with insecticides (Fig. 2) indicated that only 2 of 43 vineyards had more than five nymphs per leaf during the 1989 growing season. In 1990, 1991, and $1992,25,14$, and $9 \%$ of vineyards, respectively, had densities exceeding the arbitrary and low action threshold of five nymphs per leaf.

\section{Discussion}

Our data are consistent with the findings of Johnson (1914) and Hartzell (1913), who reported that $E$. comes adults overwinter primarily in leaf litter in areas adjoining vineyards and temporarily feed on many different host plants. They then move into vineyards within a few days once grape shoots have about three leaves (Hart- 
Table 1. Distribution of $E$. comes adults at different distances from the wooded edge of vineyards in 1989 and 1990

\begin{tabular}{|c|c|c|c|c|c|c|}
\hline \multirow[b]{2}{*}{ Year } & \multirow[b]{2}{*}{ Site $^{a}$} & \multirow[b]{2}{*}{ Month } & \multicolumn{4}{|c|}{ Mean no. of $E$. comes adults ( \pm SEM) per trap } \\
\hline & & & Woods & $\begin{array}{l}\text { Vineyard } \\
\text { edge }\end{array}$ & $\begin{array}{c}20 \mathrm{~m} \text { from } \\
\text { edge }\end{array}$ & $\begin{array}{c}50 \mathrm{~m} \text { from } \\
\text { edge }\end{array}$ \\
\hline \multirow[t]{12}{*}{1989} & Catawba & May & $27.8 \pm 13.6$ & $0.3 \pm 0.3$ & $0.0 \pm 0.0$ & $2.5 \pm 2.5$ \\
\hline & & June & $7.4 \pm 2.3$ & $0.5 \pm 0.4$ & $2.3 \pm 0.8$ & $0.8 \pm 0.3$ \\
\hline & & July & $10.1 \pm 1.8$ & $0.8 \pm 0.3$ & $1.4 \pm 0.4$ & $0.1 \pm 0.1$ \\
\hline & & Aug. & $1.4 \pm 0.5$ & $0.4 \pm 0.3$ & $0.8 \pm 0.4$ & $0.1 \pm 0.1$ \\
\hline & & Sept. & $0.3 \pm 0.2$ & $0.5 \pm 0.2$ & $0.8 \pm 0.3$ & $0.1 \pm 0.1$ \\
\hline & & Oct. & $1.1 \pm 0.6$ & $0.2 \pm 0.2$ & $0.9 \pm 0.9$ & $0.8 \pm 0.6$ \\
\hline & Diamond $^{b}$ & May & $222.5 \pm 36.3$ & $30.8 \pm 5.2$ & $18.0 \pm 6.1$ & $14.3 \pm 3.3$ \\
\hline & & June & $13.6 \pm 4.4$ & $28.3 \pm 3.8$ & $13.0 \pm 2.7$ & $9.0 \pm 1.4$ \\
\hline & & July & $6.8 \pm 2.8$ & $3.8 \pm 0.9$ & $1.1 \pm 0.4$ & $2.1 \pm 0.8$ \\
\hline & & Aug. & $1.2 \pm 0.5$ & $1.6 \pm 0.8$ & $2.9 \pm 1.5$ & $0.6 \pm 0.4$ \\
\hline & & Sept. & $1.0 \pm 0.4$ & $0.8 \pm 0.6$ & $1.0 \pm 0.6$ & $0.7 \pm 0.5$ \\
\hline & & Oct. & $5.1 \pm 2.1$ & $1.8 \pm 0.7$ & $1.1 \pm 0.5$ & $1.3 \pm 0.5$ \\
\hline \multirow[t]{20}{*}{1990} & Catawba & May & $11.3 \pm 7.7$ & $0.6 \pm 0.3$ & $0.5 \pm 0.3$ & $0.6 \pm 0.3$ \\
\hline & & June & $4.3 \pm 0.5$ & $1.0 \pm 1.3$ & $2.8 \pm 1.1$ & $2.7 \pm 1.5$ \\
\hline & & July & $3.0 \pm 0.3$ & $0.5 \pm 0.7$ & $1.8 \pm 0.8$ & $5.9 \pm 2.1$ \\
\hline & & Aug. & $2.0 \pm 0.1$ & $0.1 \pm 0.8$ & $1.4 \pm 0.8$ & $1.6 \pm 0.5$ \\
\hline & & Sept. & $2.0 \pm 1.2$ & $2.8 \pm 1.0$ & $1.3 \pm 0.6$ & $0.8 \pm 0.5$ \\
\hline & Delaware & May & $7.0 \pm 3.0$ & $5.5 \pm 2.5$ & $0.0 \pm 0.0$ & $1.0 \pm 0.0$ \\
\hline & & June & $1.5 \pm 0.5$ & $2.0 \pm 0.5$ & $5.6 \pm 1.2$ & $1.6 \pm 0.4$ \\
\hline & & July & $0.6 \pm 0.3$ & $1.9 \pm 1.3$ & $1.6 \pm 0.4$ & $0.6 \pm 0.4$ \\
\hline & & Aug. & $0.8 \pm 0.3$ & $0.5 \pm 0.2$ & $6.3 \pm 0.1$ & $1.1 \pm 0.4$ \\
\hline & & Sept. & 0.0 & 0.0 & 0.0 & 0.0 \\
\hline & Concord-1 & May & $40.8 \pm 21.3$ & $11.3 \pm 6.6$ & $3.2 \pm 1.3$ & $3.5 \pm 3.1$ \\
\hline & & June & $3.1 \pm 0.8$ & $2.9 \pm 1.2$ & $3.0 \pm 1.2$ & $1.3 \pm 0.5$ \\
\hline & & July & $8.4 \pm 2.2$ & $3.1 \pm 0.9$ & $2.0 \pm 0.8$ & $1.8 \pm 0.4$ \\
\hline & & Aug. & $2.8 \pm 0.9$ & $2.1 \pm 0.7$ & $2.9 \pm 1.1$ & $2.0 \pm 0.6$ \\
\hline & & Sept. & $4.8 \pm 2.7$ & $1.0 \pm 0.5$ & $0.8 \pm 0.3$ & $0.2 \pm 0.2$ \\
\hline & & Oct. & $17.6 \pm 3.5$ & $4.5 \pm 0.8$ & $2.8 \pm 1.3$ & $4.5 \pm 1.4$ \\
\hline & Concord-2 & May & $17.7 \pm 3.6$ & $1.2 \pm 0.5$ & $13.8 \pm 4.5$ & $15.5 \pm 3.9$ \\
\hline & & June & $9.5 \pm 2.3$ & $1.3 \pm 0.4$ & $3.6 \pm 0.8$ & $10.5 \pm 2.8$ \\
\hline & & July & $10.5 \pm 4.7$ & $4.0 \pm 1.4$ & $3.9 \pm 1.0$ & $12.4 \pm 5.3$ \\
\hline & & Aug. & $4.0 \pm 2.2$ & $0.9 \pm 0.4$ & $2.6 \pm 1.0$ & $9.0 \pm 5.2$ \\
\hline
\end{tabular}

${ }^{a}$ Vineyard sites are named for grape variety planted there.

'Mixed planting of 'Dutchess' (first eight rows) and 'Diamond' (remainder of vineyard).

zell 1913, Johnson 1914). The number of leafhopper adults we trapped was highest at the wooded edges early in the season, and average trap catches were consistently highest in May (Fig. 1). Few adults were captured in midseason, which is when nymphs mature into adults, even in vineyards with high densities of nymphs (Fig. 1C). Low adult trap catches in midseason were not attributable to declining densities of adults. In vineyards surveyed, we observed that adults became more abundant as the season progressed and first-brood nymphs matured into adults. We hypothesize that reduced movement, reduced attractiveness of the traps relative to grape foliage, or a combination of these two factors resulted in extremely low trap catches of adults.

The first appearance of nymphs occurred within a narrow range of $6 \mathrm{~d}$ during $3 \mathrm{yr}$, despite the fact that thermal unit accumulation and vine phenology varied greatly among years. In 1989 and 1990, thermal unit accumulations were near their long-term averages in New York. In 1991, degree-day accumulations in April and May were about double the long-term average. Early accumulation of thermal units in 1991 was reflected in vine phenology, with bud break occurring on 26 April, $14 \mathrm{~d}$ before normal. Bloom oc- curred on 31 May, $16 \mathrm{~d}$ before the long-term average bloom date for 'Concord' vines. However, despite accelerated vine development during 1991, the warmer conditions did not result in earlier oviposition than that which occurs in average years, as reflected in first observation dates for nymphs. This suggests that, in addition to degree-day accumulations, other factors regulate the start of oviposition and subsequent appearance of leafhopper nymphs in vineyards. Cate (1975) postulated that photoperiod influenced termination of reproductive diapause in E. elegantula, a closely related species in the western United States. A similar critical photoperiod may regulate the start of ovarian development in E. comes.

Within-vineyard nymphal distribution varied among vineyards and years. In the six vineyards sampled in 1989 and 1990 (Table 3), nymphal densities did not decline with increasing distance from the vineyard edge. In the 12 vineyards evaluated in 1991, however (Table 4), nymphal densities were significantly higher at vineyard edges in July than in vineyard interiors (>20 vines from the edge). This 1991 result suggests that adults were aggregated at the wooded edges at the beginning of the growing season and 
Table 2. Calendar date and degree-day accumulations for first appearance and peak densities of first- and secondgeneration nymphs of $E$. comes

\begin{tabular}{|c|c|c|c|c|c|c|c|}
\hline \multirow[b]{2}{*}{ Year } & \multirow[b]{2}{*}{ Vineyard } & \multicolumn{3}{|c|}{ Calendar date } & \multicolumn{3}{|c|}{ Degree-days $^{a}$} \\
\hline & & $\begin{array}{c}\text { First } \\
\text { nymphs }\end{array}$ & First peak ${ }^{c}$ & Second peak & $\begin{array}{c}\text { First } \\
\text { nymphs }^{b}\end{array}$ & $\begin{array}{c}\text { First } \\
\text { peak }^{c}\end{array}$ & $\begin{array}{c}\text { Second } \\
\text { peak }\end{array}$ \\
\hline \multirow[t]{2}{*}{1989} & 1 & 12 June & - & 15 Aug. & 287 & - & 1,017 \\
\hline & 2 & 26 June & - & 7 Aug. & 395 & - & 887 \\
\hline \multirow[t]{5}{*}{1990} & 1 & 11 June & 10 July & 23 Aug. & 264 & 561 & 1,031 \\
\hline & 2 & 11 June & 17 July & 23 Aug. & 264 & 629 & 1,031 \\
\hline & 3 & - & - & 5 Sept. & - & - & 1,164 \\
\hline & 4 & 18 June & - & 23 Sept. & 388 & - & 1,356 \\
\hline & 5 & 18 June & - & 23 Sept. & 388 & - & 1,356 \\
\hline \multirow[t]{7}{*}{1991} & 1 & 13 June & $17 \mathrm{July}$ & 23 Aug. & 450 & 813 & 1,250 \\
\hline & 2 & 13 June & 27 June & 8 Aug. & 450 & 609 & 1,079 \\
\hline & 3 & 13 June & 11 July & 23 Aug. & 450 & 756 & 1,335 \\
\hline & 4 & 13 June & $3 \mathrm{July}$ & 30 Aug. & 450 & 658 & 1,335 \\
\hline & 5 & 12 June & $10 \mathrm{July}$ & 24 Aug. & 424 & 646 & 1,254 \\
\hline & 6 & 12 June & 25 June & 29 Aug. & 424 & 552 & 1,316 \\
\hline & 7 & 13 June & 29 June & 23 Aug. & 430 & $6 \mathrm{II}$ & 1,244 \\
\hline 1989 & Mean & 19 June & - & 11 Aug. & 341 & - & 952 \\
\hline 1990 & Mean & 14 June & 13 July & 7 Sept. & 326 & 595 & 1,188 \\
\hline 1991 & Mean & 12 June & 4 July & 22 Aug. & 440 & 664 & 1,259 \\
\hline \multirow[t]{2}{*}{ All years } & Mean & 14 June & 6 July & 26 Aug. & 390 & 648 & 1,190 \\
\hline & $\mathrm{SD}^{d}$ & 4 & 8 & 14 & 71 & 86 & 154 \\
\hline
\end{tabular}

a Degree-day accumulations after 1 April above thermal threshold of $10^{\circ} \mathrm{C}$ as measured at nearby weather stations.

b. Indicates nymphs found in first sample taken on 15 June.

c - Indicates that no first-generation peak was identifiable.

a SD expressed in days (calendar date) or degree-days.

dispersed only limited distances before beginning to oviposit. Subsequent diffusion of adults through the vineyard appears to have led to more even distribution of nymph populations later in the season. Disparity between the 1989 and 1990 results and the 1991 results may have reflected

Table 3. Within-vineyard distribution of $E$. comes nymphs at different distances from wooded edges of vineyards sampled in 1989 and 1990

\begin{tabular}{|c|c|c|c|c|c|c|c|c|c|c|}
\hline \multirow{2}{*}{ Year } & \multirow{2}{*}{ Vineyard } & \multirow{2}{*}{ Month } & \multirow{2}{*}{$F^{a}$} & \multirow{2}{*}{$\mathrm{df}$} & \multirow{2}{*}{$P^{a}$} & \multicolumn{5}{|c|}{ Mean no. of $E$. comes nymphs ( \pm SEM) per shoot } \\
\hline & & & & & & Vine $1^{b}$ & Vine 3 & Vine 5 & Vine 10 & Vine 20 \\
\hline \multirow[t]{10}{*}{1989} & Catawba $^{c}$ & June & 1.00 & 4,39 & 0.41 & $0.0 \pm 0.0$ & $0.0 \pm 0.0$ & $0.0 \pm 0.0$ & $0.1 \pm 0.1$ & $0.0 \pm 0.0$ \\
\hline & & July & 1.13 & 4,39 & 0.35 & $2.6 \pm 1.1$ & $2.9 \pm 0.8$ & $3.1 \pm 0.9$ & $2.1 \pm 0.7$ & $1.4 \pm 0.8$ \\
\hline & & Aug. & 0.29 & 4,39 & 0.88 & $4.5 \pm 1.1$ & $3.6 \pm 0.8$ & $4.8 \pm 0.9$ & $4.6 \pm 0.7$ & $4.5 \pm 0.8$ \\
\hline & & Sept. & 0.48 & 4,39 & 0.75 & $2.7 \pm 0.7$ & $2.6 \pm 0.4$ & $2.4 \pm 0.4$ & $3.4 \pm 0.7$ & $3.2 \pm 0.5$ \\
\hline & & Oct. & 2.02 & 4,39 & 0.10 & $0.5 \pm 0.2$ & $0.3 \pm 0.1$ & $0.2 \pm 0.1$ & $1.0 \pm 0.3$ & $0.8 \pm 0.3$ \\
\hline & Diamond $^{c}$ & June & 0.93 & 4,65 & 0.44 & $0.1 \pm 0.1$ & $0.1 \pm 0.1$ & $0.0 \pm 0.0$ & $0.0 \pm 0.0$ & $0.0 \pm 0.0$ \\
\hline & & July & 4.76 & 4,65 & $<0.001$ & $1.4 \pm 0.3$ & $2.2 \pm 0.3$ & $1.7 \pm 0.2$ & $3.4 \pm 0.7$ & $4.5 \pm 0.9$ \\
\hline & & Aug. & 26.4 & 4,65 & $<0.001$ & $0.9 \pm 0.2$ & $1.4 \pm 0.2$ & $1.0 \pm 0.2$ & $5.5 \pm 0.6$ & $11.0 \pm 1.7$ \\
\hline & & Sept. & 1.86 & 4,65 & 0.11 & $0.8 \pm 0.2$ & $0.7 \pm 0.2$ & $0.6 \pm 0.1$ & $1.1 \pm 0.2$ & $1.3 \pm 0.3$ \\
\hline & & Oct. & 0.83 & 4,65 & 0.25 & $0.3 \pm 0.1$ & $0.1 \pm 0.1$ & $0.2 \pm 0.0$ & $0.2 \pm 0.1$ & $0.3 \pm 0.1$ \\
\hline \multirow[t]{17}{*}{1990} & Catawba & June & 0.46 & 4,55 & 0.76 & $0.6 \pm 0.4$ & $0.4 \pm 0.2$ & $0.8 \pm 0.3$ & $0.8 \pm 0.3$ & $0.3 \pm 0.1$ \\
\hline & & July & 1.74 & 4,55 & 0.15 & $18.4 \pm 3.6$ & $27.4 \pm 4.9$ & $32.4 \pm 4.3$ & $22.3 \pm 3.0$ & $23.9 \pm 4.0$ \\
\hline & & Aug. & 10.1 & 4,55 & $<0.001$ & $17.3 \pm 1.9$ & $29.3 \pm 3.2$ & $39.8 \pm 4.4$ & $35.2 \pm 3.1$ & $43.5 \pm 3.1$ \\
\hline & & Sept. & 6.65 & 4,55 & $<0.001$ & $4.3 \pm 0.7$ & $7.7 \pm 1.3$ & $9.4 \pm 1.5$ & $10.0 \pm 1.2$ & $14.0 \pm 1.8$ \\
\hline & Delaware & June & 1.23 & 4,55 & 0.30 & $0.4 \pm 0.1$ & $0.4 \pm 0.1$ & $0.3 \pm 0.1$ & $0.8 \pm 0.2$ & $0.6 \pm 0.2$ \\
\hline & & July & 8.50 & 4,55 & 0.002 & $4.4 \pm 0.6$ & $5.6 \pm 0.8$ & $5.4 \pm 0.9$ & $8.0 \pm 1.1$ & $12.4 \pm 1.7$ \\
\hline & & Aug. & 8.04 & 4,55 & 0.001 & $2.7 \pm 0.4$ & $4.4 \pm 0.5$ & $4.8 \pm 0.5$ & $6.8 \pm 0.7$ & $7.2 \pm 0.9$ \\
\hline & & Sept. & 1.08 & 4,55 & 0.37 & $1.5 \pm 0.3$ & $2.2 \pm 0.4$ & $1.9 \pm 0.3$ & $2.6 \pm 0.4$ & $2.1 \pm 0.3$ \\
\hline & Concord-1 & June & 1.42 & 4,55 & 0.24 & $0.2 \pm 0.1$ & $0.1 \pm 0.1$ & $0.0 \pm 0.0$ & $0.0 \pm 0.0$ & $0.0 \pm 0.0$ \\
\hline & & July & 2.99 & 4,55 & 0.01 & $0.2 \pm 0.1$ & $0.4 \pm 0.1$ & $0.9 \pm 0.2$ & $1.0 \pm 0.3$ & $0.3 \pm 0.1$ \\
\hline & & Aug. & 4.07 & 4,55 & 0.005 & $0.3 \pm 0.1$ & $0.9 \pm 0.2$ & $2.7 \pm 0.6$ & $2.5 \pm 0.7$ & $2.3 \pm 0.6$ \\
\hline & & Sept. & 5.68 & 4,55 & $<0.001$ & $1.8 \pm 0.7$ & $4.3 \pm 1.0$ & $7.9 \pm 1.7$ & $9.6 \pm 1.8$ & $9.9 \pm 1.8$ \\
\hline & Concord-2 & June & 1.55 & 4,55 & 0.19 & $0.2 \pm 0.1$ & $0.3 \pm 0.1$ & $0.4 \pm 0.1$ & $0.1 \pm 0.1$ & $0.1 \pm 0.0$ \\
\hline & & July & 16.6 & 4,55 & $<0.001$ & $2.9 \pm 0.4$ & $7.7 \pm 0.9$ & $11.1 \pm 1.5$ & $13.2 \pm 1.8$ & $2.3 \pm 0.6$ \\
\hline & & Aug. & 15.8 & 4,55 & $<0.001$ & $5.4 \pm 0.6$ & $7.1 \pm 0.7$ & $10.1 \pm 1.4$ & $11.6 \pm 1.3$ & $1.8 \pm 0.3$ \\
\hline & & Sept. & 4.89 & 4,55 & 0.01 & $36.6 \pm 3.0$ & $34.2 \pm 2.6$ & $34.3 \pm 3.5$ & $50.2 \pm 5.5$ & $28.3 \pm 2.9$ \\
\hline & & Oct. & 1.51 & 4,55 & 0.20 & $35.5 \pm 6.1$ & $32.9 \pm 3.5$ & $29.1 \pm 3.2$ & $46.5 \pm 6.6$ & $34.7 \pm 5.7$ \\
\hline
\end{tabular}

${ }^{a} F$ statistic and $P$ values from analysis of variance with vine number as a categorical treatment factor.

$b$ Vine 1 was at the edge of the vineyard; vine spacing was $2.5 \mathrm{~m}$.

${ }^{\circ} n=12$ transects; except Catawba $1989(n=8)$ and Diamond $1989(n=14)$. 
Table 4. Mean number of $E$. comes nymphs per shoot at edge and interior sampling areas in 12 pheromone-treated vineyards in 1991

\begin{tabular}{|c|c|c|c|c|c|c|}
\hline \multirow{3}{*}{ Vineyard } & \multicolumn{6}{|c|}{ Leafhopper nymphs per shoot $( \pm \mathrm{SEM})^{a}$} \\
\hline & \multicolumn{2}{|c|}{ June $^{b}$} & \multicolumn{2}{|c|}{ July } & \multicolumn{2}{|c|}{ August $^{d}$} \\
\hline & Edge & Interior & Edge & Interior & Edge & Interior \\
\hline 1 & $0.0 \pm 0.0$ & $0.0 \pm 0.0$ & $1.4 \pm 0.4$ & $0.4 \pm 0.2$ & $8.0 \pm 2.2$ & $7.4 \pm 2.0$ \\
\hline 2 & $0.2 \pm 0.5$ & $0.1 \pm 0.1$ & $9.4 \pm 2.3$ & $4.1 \pm 0.9$ & $17.8 \pm 6.6$ & $14.9 \pm 4.8$ \\
\hline 3 & $0.2 \pm 0.1$ & $0.2 \pm 0.2$ & $6.6 \pm 1.4$ & $1.8 \pm 0.6$ & $4.6 \pm 1.1$ & $7.2 \pm 2.3$ \\
\hline 4 & $0.1 \pm 0.4$ & $0.0 \pm 0.0$ & $1.8 \pm 0.3$ & $0.4 \pm 0.2$ & $6.7 \pm 1.3$ & $3.7 \pm 1.0$ \\
\hline 5 & $0.0 \pm 0.0$ & $0.0 \pm 0.0$ & $0.4 \pm 0.2$ & $0.1 \pm 0.1$ & $2.9 \pm 1.0$ & $0.7 \pm 0.4$ \\
\hline 6 & $0.0 \pm 0.0$ & $0.0 \pm 0.0$ & $3.5 \pm 0.8$ & $1.4 \pm 2.0$ & $2.8 \pm 0.9$ & $2.3 \pm 2.2$ \\
\hline 7 & $0.4 \pm 0.1$ & $0.1 \pm 0.4$ & $8.0 \pm 1.8$ & $2.7 \pm 0.4$ & $1.9 \pm 0.7$ & $3.5 \pm \mathrm{J} .6$ \\
\hline $8^{e}$ & $0.0 \pm 0.0$ & $0.0 \pm 0.0$ & $11.6 \pm 3.6$ & $10.7 \pm 5.2$ & - & - \\
\hline $9^{e}$ & $0.1 \pm 0.1$ & $0.1 \pm 0.1$ & $5.0 \pm 1.6$ & $1.0 \pm 0.5$ & 一 & - \\
\hline $10^{e}$ & $0.1 \pm 0.1$ & $0.0 \pm 0.0$ & $11.8 \pm 4.3$ & $7.6 \pm 2.8$ & - & - \\
\hline $11^{e}$ & $0.2 \pm 0.1$ & $0.0 \pm 0.0$ & $1.3 \pm 0.6$ & $0.6 \pm 0.2$ & - & - \\
\hline $12^{e}$ & $2.0 \pm 0.8$ & $1.3 \pm 0.7$ & $34.2 \pm 4.1$ & $31.1 \pm 5.3$ & - & - \\
\hline
\end{tabular}

${ }^{a} n=10$ edge and 10 interior shoots.

${ }^{b} F=2.27 ; \mathrm{df}=1,216 ; P=0.13$.

${ }^{c} F=11.05 ; \mathrm{df}=1,216 ; P<0.001$.

${ }^{d} F=0.40 ; \mathrm{df}=1,139 ; P=0.52$.

e Sampling terminated after insecticide application; -, no samples were taken in these vineyards in August.

differences in survey design or inherent variability in colonization and movement of adults before oviposition in different growing seasons. Sample units in the 1989 and 1990 surveys were concentrated in the border region $(<20$ vines from the vineyard edges). The robust trend noted at 12 vineyards in 1991, however, compared densities at edge vines to densities in sample areas greater than 20 vine lengths into the vineyard. However, it is possible that rates of movement and colonization of vineyard interiors vary among years.

Varietal preference appears to have influenced nymphal distribution at the Diamond vineyard, where leafhoppers apparently oviposited preferentially on 'Diamond', rather than on 'Dutchess'. The 7-fold difference in nymphal densities suggests that some grape cultivars are much less susceptible to leafhopper attack. Over 48 varieties of grapes, comprising cultivars of $V$. labrusca Bailey and $V$. vinifera $L$., interspecific hybrids of
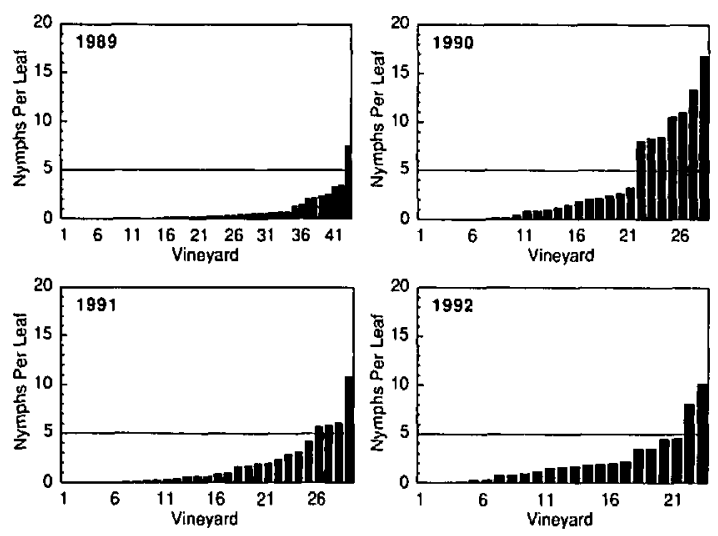

Fig. 2. Seasonally maximum densities (nymphs per leaf) of $E$. comes in central and western New York vineyards during 1989, 1990, 1991, and 1992. Line denotes the provisional threshold of five nymphs per leaf.
Vitis spp., are grown in New York. The interaction between cultivar susceptibility and varietal preference of the several Erythroneura species feeding on grapes in New York needs to be investigated further.

Distribution of adults trapped and early season distribution of nymphs clearly show that adults moved from overwintering sites in leaf litter around the perimeter of vineyards into vineyard areas. It is possible that this movement could be exploited in control programs. By applying barrier sprays around the perimeter of vineyards early in the season, growers might suppress subsequent colonization of vineyard interiors by leafhoppers. This approach may be particularly effective in vineyards under clean cultivation, which have little vegetation in which leafhoppers can overwinter. At sites where cover is available within the vineyard for overwintering adults, perimeter sprays would probably be less effective in preventing colonization.

Pest management alternatives incorporating substantial reductions in conventional insecticide applications targeted at grape berry moth have been widely adopted by New York growers. At the $65 \%$ of New York vineyards classified as at low risk for grape berry moth (Martinson et al. 1991) or where mating disruption is used, it is possible to eliminate insecticide sprays targeted at grape berry moth in most years. A major concern of grape growers in New York has been that they will have to apply treatments routinely for leafhoppers in these vineyards. Four years of data from regional leafhopper surveys, however, show that leafhoppers rarely reached high densities, even in vineyards where no insecticides had been applied. Only in $2,25,13$, and $8 \%$ of the vineyards surveyed over four seasons did nymph populations exceed the provisional treatment 
threshold of five nymphs per leaf. Although more precise treatment thresholds for $E$. comes are currently lacking, five nymphs per leaf is undoubtedly conservative in preventing economic injury to vineyards. For example, it is well below the threshold of 10 to 20 nymphs per leaf used in California vineyards (Flaherty et al. 1982).

If left for successive years without treatment, leafhopper populations could in some cases build up to economically significant levels over a period of a few years. However, before the advent of synthetic insecticides, serious outbreaks of leafhoppers occurred in less than $3 \mathrm{yr}$ in 10 (Johnson 1914, Taschenberg \& Hartzell 1949). Our data clearly illustrate that by using the threshold of five nymphs per leaf, corrective treatments can be made in the limited cases when leafhopper populations do exceed the threshold.

Simple sampling procedures are needed to assess the need to apply treatments to control leafhoppers in New York vineyards. Sampling procedures for $E$. comes need to be compatible with those developed for grape berry moth (Martinson et al. 1991). Management of grape berry moth is based on sampling in the third week in July (Martinson et al. 1991). Sampling for grape berry moth is done at two locations at the edge and two locations in the interior of each vineyard. Combining leafhopper and grape berry moth sampling would be most efficient and would allow for a treatment decision if thresholds were surpassed for either of these pests. Moreover, sampling in late July would allow growers to assess treatment needs at the time when leafhopper population trends are evident, but before the majority of foliar injury occurs, during the latter half of the season. Sampling could be based on either nymphal counts, presence-absence counts, or leaf injury ratings.

Although eastern grape leafhopper can be a damaging pest, our results suggest that economically damaging infestations are not common, even in vineyards where no insecticide applications have been made for several years. When control is necessary, either a postbloom or early August insecticide application will provide adequate suppression of this pest. The leafhopper management recommendations described herein further our efforts to reduce insecticide use in New York vineyards and serve to illustrate to growers that secondary pests do not justify returning to preventive insecticide use to control arthropods in New York vineyards.

\section{Acknowledgments}

We acknowledge Tim Weigle (New York State IPM program), James Kamas (Cornell Cooperative Extension), and Rick Dunst, Christine Cummings, and Ted
Taft, Jr. (Comell's E. F. Taschenberg Vineyard Laboratory) for their assistance in these studies. Sara Martini, Steve Lefko, and Paul Castelluzo assisted with data collection. These studies were funded, in part, by the New York Wine and Grape Foundation, the New York State Integrated Pest Management Program, and the Kaplan Vineyard Fund.

\section{References Cited}

Baskerville, G. L. \& P. Emin. 1969. Rapid estimation of heat unit accumulation from maximum and minimum temperatures. Ecology 50: 514-517.

Cate, J. R. 1975. Ecology of Erythroneura elegantula Osborn (Homoptera: Cicadellidae) in grape agroecosystems in California. Ph.D. dissertation, University of California, Berkeley.

Dennehy, T. J., L. G. Clark \& J. S. Kamas. 1991. Pheromonal control of the grape berry moth: an effective alternative to conventional insecticides. N.Y. Food Life Sci. Bull. 135.

Flaherty, D. L., F. L. Jensen, A. N. Kasimatis, H. Kido \& W. J. Moller. 1982. Grape pest management. Univ. Calif. Div. Agric. Sci. Publ. 4105.

Hartzell, F. Z. 1913. The grape leaf-hopper. N.Y. State Agric. Exp. Stn. Geneva Bull. 359.

Hoffman, C. J. \& T. J. Dennehy. 1987. Assessing the risk of grape berry moth attack in New York vineyards. N.Y. Food Life Sci. Bull. 120.

1989. Phenology, movement, and within-field distribution of the grape berry moth, Endopiza viteana (Clemens) (Lepidoptera: Tortricidae), in New York vineyards. Can. Entomol. 121: 325-335.

Johnson, F. 1914. The grape leafhopper in the Lake Erie valley. U.S. Dep. Agric. Bull. 19.

Jubb, G. L., Jr., L. Danko \& C. W. Haeseler. 1983. Impact of Erythroneura comes Say (Homoptera: Cicadellidae) on caged 'Concord' grapevines. Environ. Entomol. 12: 1576-1580.

Martinson, T. E., C. J. Hoffman, T. J. Dennehy, J. S. Kamas \& T. Weigle. 1991. Risk assessment of grape berry moth and guidelines for management of the eastern grape leafhopper. N.Y. Food Life Sci. Bull. 138.

Pool, R. M., R. E. Dunst, D. C. Crowe, H. Hubbard, G. E. Howard \& G. DeGolier. 1993. Predicting and controlling crop on machine or minimal pruned grapevines, pp. 31-45. Proceedings, Second Nelson J. Shaulis Symposium. New York State Agricultural Experiment Station, Cornell University, Geneva, NY.

Taschenberg, E. F. 1948. Evaluation of spray programs for control of grape berry moth, Polychrosis viteana, Clems. N.Y. State Agric. Exp. Stn. Tech. Bull. 283.

Taschenberg, E. F. \& F. Z. Hartzell. 1949. Grape leafhopper control-1944 to 1947. N.Y. State Agric. Exp. Stn. Bull. 738 .

Van Kirk, J., H. Riedl \& E. F. Taschenberg. 1984. Grape leafhopper. Grape IPM Insect Identification Sheet No. 4. New York State Agricultural Experiment Station, Cornell University, Geneva, NY.

Received for publication 5 March 1993; accepted 8 October 1993. 